\section{Motivation: Theory/Human Model}

Emilia Cabras ${ }^{1}$ and Sofia von Humboldt ${ }^{2}$

${ }^{1}$ CES Don Bosco - Centro de Enseñanza Superior en Humanidades y Ciencias de la Educación, Madrid, Spain

${ }^{2}$ William James Center for Research, ISPA Instituto Universitário, Lisbon, Portugal

\section{Synonyms}

Drive; Goals; Incentives; Motive; Purpose; Reason; Stimulus

\section{Definition}

Motivation is a determinant of human behavior characterized as an instinctual drive that entices an individual to reach a task or goal organized into a hierarchy of needs, from basic physiological needs to the need for self-actualization (Maslow 1970).

\section{Overview}

Motivational factors are an important component of aging well (See $>$ "Aging Well"), and regulation of motivation optimizes development throughout life. Interest in studies related to motivation in old age, particularly perspectives on aging, development, and life-span research, is growing (Braver et al. 2014). A classical theoretical framework of motivation is self-determination theory (SDT), which identifies fundamental psychological needs in the life course. Satisfaction of these basic needs supports healthy motivation and psychological well-being, promoting activity and growth in older adults (Ryan and Deci 2000) (See $>$ "Health and Aging").

According to traditional theories of life-span development (See $>$ "Life-Span Development"), such as the selection, optimization, and compensation (SOC) model (See $\triangleright$ "Selection, Optimization, and Compensation, The Model of'), late-life changes reflect adaptations to the potential negative dynamic between gains and losses (Baltes and Baltes 1990). This model's motivational perspective postulates that individuals, depending on the availability of resources, focus on achieving goals to maximize gains and minimize losses (Knecht and Freund 2017) (See "Successful Aging 2.0"). Regulation of motivation is, therefore, a central feature of individuals' adaptive capacity to optimize development through the main changes that occur in late life (Heckausen et al. 2019).

Socioemotional selectivity theory (SST) is a life-span theory of motivation that postulates that the perceived time horizon decreases as age progresses, with implications in shaping goal setting and goal pursuit (See $>$ "Socioemotional Selectivity Theory"). Older people become selective in 
social relationships and focus on meaningful relationships, prioritizing motivational shifts that favor goals related to emotional well-being. Furthermore, older adults report reduced levels of negative affective experience and preserved levels of positive experience compared to younger adults, resulting in decreased attention to and memory of negative versus positive material; these changes may have implications for shifts in motivational goals (Carstensen 2006; Giasson et al. 2018).

Age-related cognitive changes seem to influence motivational factors. Increased mental effort and costs associated with cognitive engagement negatively impact older adults' motivation to engage in effortful cognitive activities in everyday life (Hess 2014) (See $\triangleright$ "Selective Engagement of Resources"). The interaction of motivation and cognitive control has proven particularly important to understand goal-directed behaviors in aging (Braver et al. 2014).

In December 2019, the Covid-19 pandemic emerged. Social distancing is an effective measure to restrain the spread of infections; however, older adults are highly susceptible to isolation, with a high mental health burden (Bavel et al. 2020; Newman et al. 2020). Motivation can be an important mechanism that modulates the behavior of older people during the Covid-19 emergency. They may show a high level of concern for the virus, thereby increasing behaviors related to fear. However, in contrast to younger people, they may tend to avoid isolation, reflecting the motivation to resolve a psychological conflict (characterized by the urge to take action against a feeling of concern) by maintaining a normal lifestyle (Bacon and Corr 2020).

\section{Key Research Findings}

In later life, motivation results to be especially related to affect and cognitive factors. As individual aged, there is a focus on motivational reprioritization, where older individuals perceive that time horizons are limited and as consequence increase engaging in meaningful activities and give priority to closest social relations; older adults select behavioral goals that are associated to positive affect and have high self-relevance. This period of shifting motivational goals avoids engagement in cognitive effortful activities or those that induce negative affect (Giasson et al. 2018).

Research on human motivation theory can be applied in diverse areas, such as health and lifelong learning in old age. Age-related change in motivation can influence older adults' decisionmaking, so evidence can be useful when constructing interventions to increase motivation in behavior related to active aging (Strough et al. 2015). Motivational factors are implied to increase older adults' healthy behaviors, such as participating in exercise programs (Biedenweg et al. 2014), walking (Notthoff and Carstensen 2014), participating in team sports (Pedersen et al. 2017), engaging in cognitively demanding everyday activities (Hess et al. 2018), or engaging in activities such as volunteer work (Giasson et al. 2018) (See $\triangleright$ "Psychological Theories of Health Aging").

\section{Future Directions of Research}

Future research should integrate progress in neurocognitive, social/personality, and life-span perspectives, to examine the interaction of affect and cognitive factors and their influence on motivational factors in old age (Braver et al. 2014). Individual motivational self-regulation requires more research, as do choice of relevant goals, the role of emotions and goal engagement, and disengagement in later life (Heckausen et al. 2019). Motivation factors play an important role in interventions and may increase motivation in behavior related to healthy and active aging. Further evidence is necessary to test the effectiveness of interventions that improve health behavior decisionmaking in older adults (Strough et al. 2015).

\section{Cross-References}
Aging Well
- Covid-19 Pandemic and Healthy Aging
- Healthy Aging 
Life-Span Development

- Psychological Theories of Health and Aging

- Selective Engagement of Resources

- Selective Optimization with Compensation Theory

- Selection, Optimization, and Compensation, The Model of

- Socioemotional Selectivity Theory

- Successful Aging 2.0

\section{References}

Bacon AM, Corr PJ. (2020) Coronavirus (COVID-19) in the United Kingdom: A personality-based perspective on concerns and intention to self-isolate [published online ahead of print, $2020 \mathrm{Apr} 29]$. Br J Health Psychol https://doi.org/10.1111/bjhp.12423

Baltes PB, Baltes M (eds) (1990) Successful aging: perspectives from the behavioral sciences. European network on longitudinal studies on individual development. Cambridge University Press, Cambridge

Bavel JJV et al (2020) Using social and behavioural science to support COVID-19 pandemic response. Nat Hum Behav 4:460-471 https://doi.org/10.1038/s41562-0200884-Z

Biedenweg $\mathrm{K}$ et al (2014) Understanding older adults' motivators and barriers to participating in organized programs supporting exercise behaviors. J Prim Prev 35:1-11. https://doi.org/10.1007/s10935-013-0331-2

Braver TS et al (2014) Mechanisms of motivation-cognition interaction: challenges and opportunities. Cogn Affect Behav Neurosci 14(2):443-472. https://doi.org/10.3758/ s13415-014-0300-0

Carstensen LL (2006) The influence of a sense of time on human development. Science 312:1913-1915. https:// doi.org/10.1126/science. 1127488

Giasson HL, Liao HW, Carstensen LL (2018) Counting down while time flies: implications of age-related time acceleration for goal pursuit across adulthood. Curr Opin Psychol 10(26):85-89. https://doi.org/10.1016/j. copsyc.2018.07.001

Heckhausen J, Wrosch C, Schulz R (2019) Agency and motivation in adulthood and old age. Annu Rev Psychol 70:13.1-13.27. https://doi.org/10.1146/annurev-psych010418-103043

Hess TM (2014) Selective engagement of cognitive resources: motivational influences on older adults' cognitive functioning. Perspect Psychol Sci 9(4):388-407. https://doi.org/10.1177/1745691614527465

Hess TM, Growney CM, O'Brien EL et al (2018) The role of cognitive costs, attitudes about aging, and intrinsic motivation in predicting engagement in everyday activities. Psychol Aging 33(6):953-964. https://doi.org/ 10.1037/pag0000289

Knecht M, Freund AM (2017) The use of selection, optimization, and compensation (SOC) in goal pursuit in the daily lives of middle-aged adults. Eur J Dev Psychol 14:350-366. https://doi.org/10.1080/17405629.2016.12 07518

Maslow AH (1970) Motivation and personality. Harper \& Row, New York

Newman MG, Zainal NM (2020) The value of maintaining social connections for mental health in older people. Lancet Pub. Health 5(1):e12-e13 https://doi.org/ 10.1016/S2468-2667(19)30253-1

Notthoff N, Carstensen LL (2014) Positive messaging promotes walking in older adults. Psychol Aging 29:329-341. https://doi.org/10.1037/a0036748

Pedersen MT, Vorup J, Nistrup A et al (2017) Effect of team sports and resistance training on physical function, quality of life, and motivation in older adults. Scand J Med Sci Sports 27(8):852-864. https://doi. org/10.1111/sms.12823

Ryan R, Deci E (2000) Self-determination theory and the facilitation of intrinsic motivation, social development, and wellbeing. Am Psychol 55:68-78. https://doi.org/ 10.1037/0003-066X.55.1.68

Strough J, Bruine de Bruin W, Peters E (2015) New perspectives for motivating better decisions in older adults. Front Psychol 6:783. https://doi.org/10.3389/fpsyg.2015.00783 